\title{
EL ACEITE EN LA BAJA EDAD MEDIA: SU USO INDUSTRIAL. LAS COMARCAS DEL SUR VALENCIANO Y EL DESARROLLO DE LA PAÑERÍA (SEGUNDA MITAD DEL SIGLO XV)
}

\author{
OIL IN THE LATE MIDDLE AGES: INDUSTRIAL USE: THE SOUTHERN REGIONS OF \\ VALENCIA AND THE DEVELOPMENT OF THE WOOL MANUFACTURING
}

\author{
Antoni LLIBRER ESCRIG \\ Universitat de València \\ j.antonio.llibrer@uv.es
}

Resumen: Este trabajo analiza la producción y el mercado de aceite durante la baja Edad Media en las ciudades y comunidades rurales de la región interior-sur del antiguo Reino de Valencia. Esta área, articulada mediante una serie ciudades medias y pequeñas comunidades asociadas, desarrolló una gran actividad oleícola, con una producción para la industria lanera de la zona y para la venta en los mercados regionales vecinos. El artículo descubre y estudia la función de un grupo de artesanos pañeros locales en la especialización, el desarrollo y la consolidación de la olivicultura. En esta región (comarcas de la Valld'Albaida, l'Alcoià $i$ el Comtat, y algunas ciudades como Ontinyent, Alcoi y, sobre todo, Cocentaina), un reducido grupo de grandes artesanos del textil gestionaron la producción, la transformación y el comercio del aceite. Se analizan directamente las empresas de
Abstract: This work analyzes oil production and oil trade during the Later Middle Ages, in towns and rural communities in southern interior region of the Ancient Kingdom of Valencia. This rural area, articulated by towns and small communities, developed a great oil activity and trade with a production for the local woolen industry and for the market, for neighboring regional markets. The article discovers and studies the role of a group of craftsmen in the specialization, development and consolidation of oil production in this area. In this region (Valld'Albaida, Alcoià and Comtat, and some towns such as Ontinyent, Alcoi and specifically Cocentaina), a small group of big craftsmen were able to centralize management of oil activities through direct participation in this production and market. The article analyzes directly the artisans and their enterprises, their 
estos artesanos, sus negocios y sus inversiones oleícolas para entender la función económica de esta actividad.

Palabras clave: aceite, industria lanera, artesanos emprendedores, mercado regional, siglo XV businesses and their investments, to understand the economic function of this activity.

Key words: oil, woolen industry, enterprising artisans, regional market, $15^{\text {th }}$ century.

\section{Introducción: aceite y manufactura ${ }^{1}$}

Todavía hoy resulta paradójico que el estudio de la producción, el comercio y los usos del aceite en época medieval y moderna haya suscitado un interés tan limitado por parte de la historiografía peninsular. Algunos comentarios breves y algunos apuntes impresionistas en obras generales (García de Cortázar, 1988: 215; García Sanz y Sanz, 1998: 24;Benassar, 2001: 133), y muy pocos estudios concretos, sin apenas monografias, conforman un bagaje a todas luces muy escaso para la trascendencia socioeconómica de este producto de enormes posibilidades y funcionalidad.

En otros ámbitos europeos se ha llevado a cabo, desde hace décadas, un importante trabajo de análisis de la producción y el mercado de aceite durante los siglos medievales, a diferentes escalas. Desde las aportaciones iniciales de Le Roy Ladurie (1966) o Melis (1977), donde la producción oleícola era tratada como un pequeño apéndice de la estructura agraria o de la industria textil, llegamos posteriormente a aquellos trabajos que individualizan el aceite como recurso económico de primer orden, tanto en ámbito rural como urbano; y en esta segunda tendencia es donde debemos situar los análisis de Amouretti y Comet (1985, 1991), o en ámbito italiano los trabajos dePini (1980), Cherubini (1998) y Pinto (2002). Alfio Cortonesi (2002 y 2005) llevó a cabo una importante labor de síntesis que se complementó en poco tiempo con la publicación de tres volúmenes colectivos, los de Brugnoli y Varanini(2006), el correspondiente a la quincuagésimocuarta «Settimana di Studio sull'Alto Medioevo», Olio e vino nell 'Alto Medioevo (2007), y más recientemente el editado por Irma Naso (2018). ${ }^{2}$

1 Orcid del autor: http://orcid.org/0000-0002-1161-6594. Este artículo nació en el marco del proyecto Entreprises rurales en Méditerranée occidentale, XIII $-X V^{e}$ siècles (ERMO), 2014-2017, organizado por la Casa Velázquez de Madrid, y coordinado por la prof. Catherine Verna (Université Paris 8).

2 En este se incluye un importante trabajo sobre la importancia del cultivo en ámbito catalán (Sabaté, 2018). 
En la península ibérica, se conoce mejor la producción y los usos del aceite en el periodo andalusí, gracias sobretodo a sus tratados agronómicos —véanse para ello los trabajos de Bolens $(1991,1996)$ o de García Sánchez (1996) - y también su actividad fiscal y mercantil (con las obras de Collantes de Terán o de González de Arce), que los procesos de producción y transformación, de los que sólo disponemos de algunos trabajos de Córdoba de la Llave (1988; 2017), la monografía de Martínez (1995), y de un puñado de trabajos de ámbito local. ${ }^{3}$

¿Indica esta escasa presencia historiográfica, como sugieren algunos autores, que el cultivo del olivo estaba restringido a parámetros autárquicos en el ámbito doméstico? ¿Quedaba el olivo fuera de los intereses estratégicos de la explotación campesina? ¿Concebía el agricultor medieval el olivo como un cultivo de poco calado y de poco peso en su empresa agraria?¿Quedaba así por ellobuena parte del aceite fuera de los circuitos mercantiles? En estas cuestiones, en este debate sobre cultivo, uso y función del aceite es donde nosotros pretendemos aportar nuevos datos para la reflexión y el análisis.

Nos trasladamos para ello a las comarcas del sur valenciano durante la segunda mitad del siglo $\mathrm{XV}$, en concreto al espacio que hoy configuran las comarcas de la Vall d'Albaida, l'Alcoià y el Comtat que, centralizado en buena medida en la villa de Cocentaina, nos ha permitido descubrir un importante espacio de cultivo y de mercado oleícola. Las fuentes, notariales y municipales, nos han posibilitado sacar a la luz no sólo un activo mercado de aceite, sino también un importante conjunto de parcelas de olivar que facilitan el acercamiento a los colectivos y a los operadores implicados en la producción y el negocio aceitero.

Para entender la trascendencia de este producto en época medieval, es necesario que recordemos también inicialmente sus funcionalidades y las enormes posibilidades que permitía. Cocina, iluminación, higiene, medicina, farmacia, cosmética, perfumería, mantenimiento de maquinaria y, sobre todo, actividades industriales de producción de jabón, trabajo del cuero, y elaboración de paños de lana. ${ }^{4}$ En relación a esta última actividad, especialmente

3 Para época moderna contamos ya con los diversos trabajos de síntesis incluidos en el monográfico de la revista Chronica nova (sobre todo, Gamero 2015; Colás 2015).

4 Resultaría difícil enumerar todas las aplicaciones que permite el aceite en todos estos ámbitos, así como sus propiedades dietético terapéuticas, ya destacadas por los tratadistas clásicos y los andalusíes (Amouretti y Comet, 1985; Pini, 1980: 120-133; García Sánchez, 1996). Un primer acercamiento a sus usos industriales en Llibrer, 2019. 
importante en estas comarcas del sur, de clara vocación lanera ya demostrada (Llibrer, 2010, 2013b), el aceite era necesario en grandes cantidades para dos operaciones básicas. Por una parte, en el primer tratamiento de la lana, tras su limpieza, se untaba la fibra con abundante aceite para que pudiera resistir mejor los movimientos de los peines y las cardas, y dejarla así con una textura óptima para las siguientes operaciones del hilado y el tejido.

Desde el punto de vista cuantitativo, hablamos, además de la necesidad de grandes cantidades de aceite para llevar a cabo estas operaciones. Como indica Iradiel (1974: 191), según las ordenanzas de la ciudad de Cuenca, de principios del siglo XVI, para el correcto cardado de un paño veinticuatreno (de 2.400 hilos en su urdimbre) eran necesarias 24,5 libras de aceite, es decir, algo más de once litros. Con una producción anual de miles de paños, ya podemos imaginar la constante demanda oleícola para estos talleres locales. Según nuestros cálculos (Llibrer, 2010, 2014a) en esta región lanera del sur valenciano (vertebrada a través de los centros de Cocentaina, Ontinyent y Alcoi), hemos contabilizado una producción anual de entre 8.000 y 10.000 paños (entre veintiunos y dieciochenos), lo que vendría a suponer una demanda anual fija de, al menos, unos 70.000 litros de aceite sólo para atajar estas tareas iniciales del tratamiento de la lana.

Por otro lado, el aceite volvía a aparecer en la elaboración del paño en sus procesos finales, y más allá del ámbito de la pequeña empresa doméstica o familiar. En la fase de acabado del textil, una de las operaciones con mayor trascendencia era el abatanado, que servía para darle al paño la consistencia, la textura y las dimensiones adecuadas. El abatanado propiciaba un estándar de calidad que permitía su acercamiento al mercado y condicionaba su precio. Podríamos decir que esta operación, junto al tintado, daba al producto un carácter merceológico elevado, y en el siglo XV ambas operaciones están ya generalizadas en nuestra región pañera (Llibrer, 2014a: 123-126).

Como es bien sabido, el abatanado se llevaba a cabo en las instalaciones de un molino propio, de un artefacto mecánico que con una o más mazas permitía el golpeo sucesivo del paño depositado en una pila con aceite, y de esta forma se conseguía la homogeneidad, el cuerpo y la textura adecuadas. Las ordenanzas conocidas no indican las cantidades necesarias de aceite para esta tarea final de enfurtir el paño, pero el número de batanes o mazas pude indicarnos la importancia que esta fase del abatanado tendrá, y además, la importante necesidad oleícola para llevarla a cabo. A finales del siglo XV, en esta zona lanera meridional valenciana llegamos a documentar hasta una treintena de 
molinos pañeros en activo (que llegaron a ser cuarenta a principios del Quinientos, Llibrer 2013); la demanda de aceite para que sus mazas pudieran acicalar los paños suponía también un intenso impacto en las áreas rurales circundantes que se iba a traducir en la consolidación de este cultivo.

Por otro lado, no podemos desvincular la producción de aceite de la infraestructura básica a la cual se asociaba, y que permitía también una interesante operatividad. En efecto es bien conocida la plural funcionalidad que las almazaras, las prensas para la aceituna, podían llevar a cabo más allá de la campaña olivarera. Allí se podían triturar todo tipo de plantas y productos, incluso caña de azúcar (Cortonesi, 2002: 154) pero, sobre todo, se realizaba la moltura del pastel, ese producto básico para el tintado de tonalidades azuladas, tan comunes en los tejidos de época medieval. Así, en determinados momentos del año, las almazaras se convertían en molinos para moler e adobar pastell (Martínez, 1995: 51-52).

En definitiva, la configuración de una interesante área olivarera en las comarcas del sur valenciano se explica no por su vertiente agraria o agroalimentaria, sino que debe ser explicada y entendida en un marco mayor de desarrollo y expansión de las actividades manufactureras del sector textil, tintóreo, jabonero y del cuero. Los protagonistas y los gestores de buena parte de esta producción y de su comercialización son, como comprobaremos también, colectivos que surgen de estas actividades artesanales.

De hecho, el comercio y la distribución de aceite estaban siempre en manos de grandes empresas mercantiles, industriales o de grandes familias de la aristocracia. En la ciudad de Valencia, en esta misma cronología, los grandes distribuidores de aceite (aceite que proviene de las comarcas del sur e incluso de Andalucía o Catalunya), son los grandes operadores mercantiles como los Spannochi, de origen sienés, los Franchi o los Vinyo, de Pisa, o los Mas y Aparici, mercaderes valencianos (Guiral, 1989: 385-388; Igual, 1995: 102103). Y en el ámbito andaluz o murciano, la producción y el comercio de aceite estaba también íntimamente relacionada con la producción y venta de paños de lana, como en la zona que proponemos, y eran miembros de la aristocracia y de la oligarquía urbana los que poseían amplias haciendas de olivar con sus molinos de aceite; aceite que en buena parte los mercaderes genoveses ponían en circulación (Collantes de Terán, 1994, 1996, 2002; Martínez, 1995; González Arce, 2010 y 2015).

Las implicaciones socioeconómicas del aceite, con sus múltiples posibilidades, son de enorme interés; las grandes compañías, operadores y familias lo 
convirtieron en estrategia de negocio; la industria lo utilizó como materia prima, y los campesinos lo vieron como alternativa laboral. El interés sobre el aceite está fuera de toda duda, y en este contexto debemos situar nuestra aportación comarcal, en un intento de reconstruir cómo funcionaba su producción y su venta en una zona concreta para conocer cuál era la función económica de este producto clave.

\section{Un proceso inicial de especialización oleícola de raíz industrial}

Sin duda, la vocación textil de esta área valenciana condicionó la extensión de la cultura oleícola hasta conformarla como una de las más amplias y productivas de toda la Corona de Aragón. A diferencia de buena parte del territorio, donde el olivo resultaba un cultivo secundario, marginal incluso hasta reducirse a una especie combinada con otros cultivos de mayor interés, en esta zona se multiplican las amplias parcelas de cultura exclusivamente oleícola. La región constituye las actuales comarcas de la Vall d'Albaida, l'Alcoià, y el Comtat, en el ámbito sur del País Valenciano. Esta zona nos aparece ya desde el último cuarto del siglo XIV y durante todo el siglo XV, como fuertemente estructurada y jerarquizada en una densa red de centros de marcada capilaridad, presidida por cuatro villas o ciudades de tamaño medio - Cocentaina, Ontinyent, Albaiday Alcoi, con entre 400 y 600 fuegos_- con una red de núcleos intermedios - Bocairent, Llutxent, Planes, Penáguila (que no llegan al millar de habitantes) — y una amplia red de comunidades rurales, alquerías y aljamas islámicas, de menos de un centenar de fuegos, pero que tuvieron un importante papel en la producción y comercio de aceite.

Esta zona del sur, además, configuró un amplio espacio manufacturero de producción de paños de alta calidad, con centenares y centenares de talleres centrados esencialmente en las villas mayores del área, pero que necesitarán el auxilio, la complementariedad económica de esta amplia zona rural circundante para el abastecimiento de los inputs necesarios a dicha producción (lana, seda, aceite, tintes...), y también para articular la mano de obra necesaria a los procesos productivos del ciclo del paño más intensivos en trabajo (como el abastecimiento y preparación de la fibra, y todas las operaciones previas al tejido). 
Hemos documentado, para la segunda mitad del siglo XV, y gracias a los análisis prosopográficos, la presencia en activo de almenos unos seiscientos artesanos del textil, y que trabajaban tanto en las grandes villas (Cocentina, Ontinyent, Alcoi, Albaida), pero también en centros menores (Bocairent, Planes, Penáguila, Agullent o Rugat). Del amplio colectivo artesanal anterior destacaban los casi trescientos pelaires que se encargaban de todo el tratamiento inicial y final del producto, y que exigían una gran cantidad de mano de obra auxiliarpara lavar, peinar, hilar y urdir la lana, y también para tundir, cardar y abatanar el paño (Llibrer, 2013: 15-19). ${ }^{5}$

En este contexto, es lógico que el aceite se convirtiera en un producto estratégico, y que el control o la gestión de su producción y su comercialización fueran objetivo de muchos artesanos. De hecho, el perfil del «mercader de aceite» de esta zona estará íntimamente asociado a los artesanos más emprendedores de esta industria pañera. El capital y toda la amplia inversión que exigía el cultivo y la producción de aceite (con el control de las parcelas de olivar, la gestión de la recolección y la propiedad de las almazaras) serán aportados por los grandes empresarios de la lana, los «señores del paño», cuyas empresas tenían la capacidad necesaria para encarar esos costes de producción y transformación (Llibrer, 2014b).

Lo que también nos muestra la documentación conservada de esta activa zona del sur, es que el cultivo del olivar, a diferencia de otras áreas rurales valencianas y de la Corona de Aragón, ocupaba un lugar básico en su estructura agraria. Aunque no podemos contabilizar, como ocurre en otras zonas, el total de la extensión de la cultura oleícola, dado que aquí no conservamos censos ni padrones de riqueza, sí es cierto que las parcelas de olivar, o la presencia de olivos complementando a otros cultivos, es aquí especialmente elevada, y supera en mucho los porcentajes de las otras áreas rurales estudiadas.

No olvidemos que al hablar del cultivo del olivar en época medieval y moderna nos referimos a dos formas distintas de cultura: por un lado, la que podríamos denominar «especializada», es decir, con parcelas ocupadas de manera completa por olivares, y sin otros cultivos complementarios; por otro, se

5 Se ha calculado que un pelaire necesitaba la actividad de unos ocho o diez de estos trabajadores o trabajadoras auxiliares (Torras, 2006: 23-36; Iradiel, 1974: 137), lo que nos llega a conformar en esta área un amplio conjunto de activos en el textil, de varios miles de trabajadores (aunque de muy distinta condición y especialización). 
articulaba en una suerte de cultura promiscua en la que se combinaba arbolado y sembradura en la misma parcela, y en la que el olivo aparecía asociado esencialmente al cereal o la viña. En el agro valenciano bajomedieval, como en otras áreas europeas estudiadas (Comet, 1991: 202-204; Cherubini, 1996: 180-188; Cortonesi, 2005: 15-18), buena parte de la olivicultura se articulaba en el segundo sistema; no obstante, comenzaron a gestarse, desde finales del siglo XIV, tentativas de configurar pequeños espacios de monocultivo oleícola. El campo de Elx estudiado por Serrano (1993), ciertas partidas en el espacio periurbano de Castelló (Domingo, 1977; Viciano, 2008), o la comarca del Comtat que hemos estudiado, son ejemplos de este proceso. La comarca del Aljarafe, ya bien conocida desde el trabajo inicial de Borrero (1983), o el campo jerezano, estudiado por Martínez Gutiérrez (2004); el desarrollo oleícola en la Plana de Urgell, Tarragona y el Baix Empordà, incluso la comarca de las Cinco Villas, al norte de Aragón (Iradiel, 1989; Bolens, 1991, Sabaté 2018), son ejemplos que permiten entender este proceso de desarrollo oleícola especializado que salpicaba diferentes áreas mediterráneas a lo largo del siglo XV. En estos espacios, el olivar no sólo ocupaba parcelas enteras, además, muchas se ubicaban en potentes áreas de regadío donde sólo los cultivos más apreciados y estratégicos tenían cabida. No olvidemos que este primer tipo implica no sólo un mayor grado de especialización, también una orientación nítidamente comercial para el aceite, y una pluralidad de destinos que lo ponen en relación a la industria textil, del cuero y del jabón.

Refiriéndonos ya en concreto al país valenciano, la extensión del olivo durante el siglo XV, no iba más allá del 10\% del área cultivada, lo más frecuente era precisamente que el olivar no llegara a ocupar más allá del 5 o el 2\% de las heredades campesinas. Pau Viciano (2012: 163-170) evalúa la estructura del agro valenciano, y tras el análisis de numerosos datos aportados por diversos autores para áreas distintas, concluye que el cereal suponía entre el 60$70 \%$ de la superficie cultivada, la viña ocupaba entre el 15-30\% de la tierra, mientras que el resto del espacio agrario era ocupado de forma más bien limitada por un conjunto de cultivos arbóreos (olivar, pero sobretodo algarrobo, moreral y otros frutales).

Sin embargo, en el ámbito de estas comarcas del sur, la estructura agraria parece aportar interesantes diferencias. El caso del campo de Elx, ya estudiado para cronología cercana a la nuestra, muestra también una amplia extensión del olivar, incluso en zonas de regadío y con importante propiedad alodial, que a principios del siglo XVII llegó a configurar más de 190 hectáreas (Serrano, 
1993 64-65). La documentación notarial nos aporta, con el apoyo de los registros municipales, informaciones muy reveladoras en este sentido ${ }^{6}$. Sólo en esta comarca del Comtat, hemos documentado, para la segunda mitad del siglo XV, un total de 659 parcelas de tierra, y han sido localizadas tanto en documentos de compraventa, en inventarios, en censales crediticios (como propiedades en aval o hipoteca), o en lindes de los actos anteriores, y todo ello en el limitado arco cronológico de 1470-1500.En este conjunto, las parcelas de olivar, o que incluyen olivares, llegan a suponer casi el $20 \%$ del total $(17,75 \%)$. Aunque el cereal contabiliza la mitad del parcelario documentado (48,55\%), la presencia del olivar es aquí importante, y no sólo porque sobrepasa con mucho la media citada del conjunto del país valenciano, sino también porque se sitúa a la misma altura que el otro cultivo clave, la viña $(18,36 \%) .{ }^{7}$ No parece haber duda: la olivicultura se iba extendiendo aquí en detrimento de otros cultivos como la higuera, la morera, el algarrobo e incluso la viña. ${ }^{8}$

Si el amplio conjunto de parcelas olivareras no fuera ya un dato determinante para confirmar una tendencia, disponemos de otros indicios que apuntan en la misma dirección: los numerosos contratos de compraventa de aceite que redactan los notarios (en muchas ocasiones de forma anticipada), o la construcción de almazaras y sus modelos de gestión, nos hablan de un mercado

6 Para que nuestro trabajo muestre realmente el impacto y la función económica que la oleicultura llegó a adquirir en esta área del interior-sur valenciano, hemos decidido centrar inicialmente la investigación en una sola comarca, la del Comtat, porque de esa forma los datos aportados (parcelas de olivar, compraventas de aceite, operadores que intervienen, etc.) nos permiten una valoración más cercana a la realidad microeconómica de las comunidades y de los colectivos implicados. A su vez, se sustenta en una doble aportación documental para una cronología ajustada (1470-1500): el conjunto de más de cuarenta libros notariales conservados para esta zona, donde destacan la veintena de amplios volúmenes del notario Guillem Peris, que trabajó en diferentes villas del área; y los libros municipales (Manuals de Consell) y judiciales (Cort de Justícia) de la villa de Cocentaina. El Archivo del Colegio de Corpus Christi (APPV), y el Archivo Municipal de Cocentaina (AMC), han permitido dicho aporte.

7 Ofrecimos tabla completa, con un análisis más detallado de los datos, en Llibrer, 2019.

8 Es difícil descubrir qué extensión de tierra es la que nos muestran todas estas parcelas documentadas dado que los notarios o los escribanos de la zona las definen siempre con el genérico de «tros» (trozo), sin especificar extensión. No obstante, un ejercicio de análisis comparado puede permitirnos un acercamiento a este espacio rural contestano. Las numerosas investigaciones llevadas a cabo sobre la estructura agraria valenciana bajomedieval y su mercado de la tierra (Furió1995; Furió y Mira 2005; Viciano 2013), concluyen que la extensión media de su parcelario estaría alrededor de unas siete $f a$ necades (algo más de media hectárea); si aplicamos este valor medio al conjunto de las 660 parcelas documentadas, podemos concluir que hablamos al menos de unas 430hectáreas para el término de Cocentaina. Este conjunto de tierras conocidas tiene su importancia silo relacionamos con una sencilla referencia posterior: recordamos que el intendente Beramendi, a finales del siglo XVIII, indicó que la huerta de Cocentaina se extendía en 195 hectáreas, y que solo allí se producían 4.500 arrobas de aceite, unos 55.000 litros (Torró, 2005: 580). 
oleícola cada vez más intenso y estratégico, que atrae la atención de los sectores más activos y emprendedores, y que será la base de un negocio que tendrá continuidad en época moderna, al menos hasta la expulsión de los moriscos, cuando el aceite se configurará como el segundo producto agrícola, en creación de valor y comercialización, tras el trigo, y por delante de la cebada, el maíz, la avena y el vino (Torró, 2005: 574-576). ${ }^{9}$

Los datos que aportamos del espacio agrario dedicado al olivar en esta zona meridional no traslucen un proceso general en todo el reino, más bien al contrario, se contraponen a otras tendencias locales estudiadas: en los términos de Catarroja, Paterna, Manises, Godella o Rocafort, por ejemplo, en la Huerta de Valencia, el olivo continuaba siendo un cultivo «marginal» (Furió y Mira, 2005; Llibrer, 1996); o en zonas de las comarcas de la Safor, la Ribera, la Valldigna, la Costera o el Camp de Túria se había convertido ya desde principios del siglo XV en un cultivo muy secundario, prácticamente «residual» (Ciscar Pallarés, 1998; Llibrer 2003).

Estos contrastes nos permiten valorar este proceso de especialización oleícola a escala comarcal que implicó a muchas comunidades rurales de esta zona (con una destacada participación del colectivo musulmán), y que generará un impacto trascendental en las economías campesinas. Pero muchas preguntas surgen en relación a esta especialización: ¿tiene la familia campesina la capacidad financiera y la capacidad de gestión para generar o consolidar este crecimiento del olivar frente a la viña y otros cultivos? ¿Quiénes son los protagonistas de este proceso de desarrollo de la cultura oleícola? En segundo lugar, ¿es la demanda de aceite lo suficientemente elevada y atractiva para condicionar tal transformación?, ¿le resulta al campesino rentable este cambio?, ¿compensa esta progresiva implantación del cultivo de la aceituna? No olvidemos que la amortización del olivar era enormemente lenta, dado que exigía casi una decena de años para generar cierta rentabilidad, a parte de la amplia exigencia de mano de obra para las numerosas operaciones anuales asociadas (Pini, 1980: 133; Pinto, 2002: 118-120).

Pero lo primero que debe ser destacado es que este proceso de implantación del olivar no depende, como tradicionalmente se ha indicado, de las condiciones climáticas o geográficas de esta zona. Hay que buscar las respuestas

9 Sólo en la comarca de l'Alcoià, vecina a la contestana, para mediados del siglo XVIII se habla ya de 304 hectáreas dedicadas al olivar, y que según Cavanilles producían unas 80.000 arrobas anuales de aceite (Torró, 2005: 583-586). 
a las preguntas anteriores en parámetros socioeconómicos en los que convergen multitud de factores clave: el desarrollo de la manufactura textil y del jabón, la producción y el mercado de la lana, la articulación de una importante demanda interior de bienes de consumo de calidad media-alta relacionada con una mejora del nivel de vida en estas áreas rurales del interior-sur valenciano (Torró, 1996; Llibrer, 2010). Todo ello contribuyó a convertir el aceite en un producto estratégico que comenzó a salir del ámbito del consumo doméstico ordinario, para transformarse en un auténtico input industrial, en un factor de producción, en una materia prima para una manufactura en crecimiento. Por esta razón, fuerion precisamente, y así lo indica constantemente la documentación, los artesanos más emprendedores, los artesanos-empresarios, los que invirtieron en la cultura del aceite mediante diferentes estrategias complementarias: la adquisición de parcelas de olivar, o su reconversión, el mantenimiento de su cultivo y su recolección, el control y la gestión de las almazaras, e incluso la comercialización del producto al por mayor (destinado tanto a otros artesanos del textil como a las familias campesinas).

Hasta tal punto esto fue así que ese sector destacado de artesanos emprendedores llegó a conformar auténticas empresas de explotación aceitunera con importante volumen de negocio. «Empresas aceituneras» que controlaron todo el proceso de producción, y así llevaron a cabo una intensa función económica, tanto mediante su influencia en la explotación agrícola, como en las instalaciones industriales de las almazaras. Ya veremos, en efecto, cómo fue el capital artesanal el que propició la inversión suficiente para consolidar esta tendencia a la especialización oleícola de estas comarcas.

\section{Las parcelas: práctica agraria y gestión}

La propiedad de las parcelas de olivar, y sus características, son lógicamente datos clave de esta producción y de su mercado. Como indicábamos, hemos documentado más de un centenar de referencias sobre este cultivo en nuestra comarca (117), y aunque no poseemos registro completo alguno de parcelas o propiedades, el conjunto localizado puede ser una buena base donde iniciar un análisis de esta peculiar cultura en la zona. Un primer dato resulta revelador: el $70 \%$ de las parcelas documentadas con olivares lo son de forma especializada, sin que en esa misma superficie aparezcan otras especies o cultivos asociados. En el campo valenciano es frecuente que el olivo sea un cultivo complementario a otros — como el cereal o la viña esencialmente-, 
y que comparta parcela con ellos (Viciano, 2012: 164-170). ${ }^{10}$ Esto denotaba una jerarquía productiva evidente entre los agricultores, que consideraban el olivo como un cultivo secundario (y sólo con destino doméstico) frente a los de mayor entidad (cereal, viña e incluso morera) que permitían mejores posibilidades de mercado. Sin embargo, en las referencias que poseemos del Comtat, la situación y la relación frente al olivo comenzaban a ser ya muy distintas. La necesidad industrial del aceite convirtió el olivo en un cultivo de primer orden y de alta rentabilidad, hizo que el capital urbano de origen artesanal se acercara a las tierras de la comarca para implementar su producción, y, así, a lo largo de todo el siglo XV, cuando la vocación pañera del área se fue consolidando, se llevó a cabo ese proceso de progresiva especialización en la olivicultura. De este modo, a partir de la segunda mitad de la centuria, la documentación comarcal ya muestra esta tendencia, esta presencia destacada de gran cantidad de parcelas, y parcelas exclusivas destinadas al olivo.

Y no sólo parcelas, hemos localizado incluso algunas heredades dedicadas al cultivo de la aceituna. Se trata de auténticas unidades agrícolas agrupadas, formadas por distintas parcelas, con la presencia de casas, corrales e incluso almazara, y donde, en efecto, el olivar era el cultivo que centralizaba la producción. Y en el campo contestano resulta interesante destacar que las cinco heredades olivareras documentadas son propiedad de pelaires. Joan Pérez de Requena, pelaire de Cocentaina, poseía una heredad (hereditatem), situada en la partida del Algar, junto al río de Alcoi, con dos casas y varias parcelas de olivares, que además eran de propiedad franca o alodial. El también pelaire vecino Pere Cebrià poseía otra heredad en la comarca, en la partida de Miralbo, con olivares, higueras y viñas. Miquel Castelló, parayre contestano, era propietario de la heredad de Albacar, que compró al también pelaire Joan Sanç por 5.000 sueldos, y que incluía al menos cuatro parcelas de olivar y cuatro casas. ${ }^{11}$

Otro elemento clave que nos habla de la importancia de la olivicultura contestana y de la trascendencia de ese proceso de especialización es la presencia de olivares en zonas de regadío. Es evidente que este cultivo no necesita riego, pero la posibilidad de incorporarlo permite un interesante aumento de los rendimientos. Que el olivar ocupe zonas de huerta no hace sino testimoniar la jerarquía y el valor que se concedía a este cultivo, y a su posterior

10 Incluso en los alrededores de la misma ciudad de Valencia, en su comarca de l'Horta, donde la demanda de aceite para el consumo urbano debía ser elevada, pocas veces se documentan campos o parcelas dedicados exclusivamente al olivar (Furió y Mira, 2005: 590-591; Esquilache, 2006: 51-52).

11 APPV, Guillem Peris, 23.806 (1481-VIII-4); 23.386 (1491-IV-26); 23.815 (1492-II-26). 
aprovechamiento industrial y mercantil. El porcentaje de estas parcelas regadas es del $11 \%$, cifra significativa por lo que supone de opción por una determinada cultura frente a otras posibilidades más frecuentes en el ámbito rural valenciano. Tal vez sea este último punto, el del riego del olivar, el que mejor indica la opción por la especialización oleícola de esta comarca, al mostrar la importancia que se concedió al negocio del aceite. ${ }^{12}$

Por otro lado, un $30 \%$ de los olivos aparecen asociados a otras especies, sobre todo, al cereal y a la viña (casi tres cuartas partes), aunque también en menor medida al moreral y a la higuera. La documentación describe con detalle esta cultura promiscua: trocum terre plantatum oliveris, vinea et diversorum arborum; trocum terre plantatum olivis, moreris, codonyers et aliorum generum arborum; trocum terre plantatum mallol cum certis oliveris.... Se conformaba así una presencia salpicada y capilar de este cultivo entre otras especies o en sus lindes por todo el territorio de la comarca; y estasasociaciones no hacen sino traducir un proceso de intensificación agrícola en la que el olivo era ya protagonista, y en la que se pone en evidencia la capacidad organizativa de la familia campesina o de los propietarios urbanos encargados de la gestión de esta producción.

Pero era la tendencia hacia la configuración de parcelas exclusivas de olivar la que determinaba la opción hacia una especialización oleícola dirigida. En la medida que se iban multiplicando estas parcelas, se iba traspasando el marco autárquico en el que se había situado el cultivo del olivo desde hacía siglos, y como parecía confirmarse por su escasa presencia en el agro o en la documentación (en contratos, compraventas, peajes, etc., donde es difícil encontrar el aceite). Los pocos olivos que se alternaban junto al cereal o las viñas, o los que se habían plantado en solitario en los lindes de las parcelas, o en algún huerto, dieron paso, a lo largo del siglo XV, a decenas y decenas de parcelas, incluso de heredades, donde el olivo era el único protagonista del paisaje, que marcaba y determinaba los ritmos y el trabajo campesinos.

El intenso trabajo anual que estas parcelas exigían es un argumento más que refuerza la tesis del crecimiento oleícola en función de parámetros especulativos (manufactura, comercio), y más allá del autoconsumo campesino. Hasta seis operaciones, y algunas con enorme exigencia de mano de obra, debían llevarse a cabo en los olivares: tras la recolección, y entre los meses de

12 También en Elx, e incluso en las áreas periurbanas de Castelló o Vila-real, se documentan olivares en regadío (Domingo, 1978; Serrano, 1993). 
enero a abril, se realizaban uno, dos o hasta tres arados de la tierra; como complemento a la labor anterior, debía practicarse, de forma manual, la cava de los pies para facilitar la limpieza de cada árbol y para que la humedad de las lluvias de la primavera penetrase en el suelo; en el verano era necesario invertir el proceso para evitar su evaporación (Borrero, 1983: 75-76); tras el trabajo en la tierra llegaba la operación clave en la planta, la poda, que exigía especialistas de alto precio, y que solía ser controlado por los mismos propietarios para su correcta ejecución y para evitar un abuso de corte para leña; la siguiente operación, durante los meses de verano a octubre, era la roza o limpieza de la parcela para evitar el riesgo de incendios, y para preparar la recolección (Martín Gutiérrez, 2004: 68-72); para evitar la excesiva maduración de la aceituna y su masiva caída, se imponía una técnica de recolección que exigía un gran aporte de mano de obra concentrada en muy poco tiempo, en apenas dos meses. Comenzando en San Martín, 11 de noviembre, la cosecha no iba más allá de principios de enero, y tanto si era realizada recogiendo a mano directamente del olivar o batiendo sus ramas con varas (y con amplios paños extendidos en el suelo), la necesidad de trabajadores era evidente. La tarea se completaba con el transporte del fruto hasta las almazaras, con la ayuda de animales. Todo el conjunto de operaciones que se realizaban en estos molinos, no hicieron sino aumentar la necesidad de una organización compleja y de unos operadores que gestionaran todas estas fases. Los artesanos emprendedores - los pelaires y pañeros citados-, asumieron el papel tanto de promoción del proceso de especialización, como de coordinación de todas las operaciones descritas, mientras aportaban el capital necesario para ponerlas en funcionamiento.

$\mathrm{Y}$ esta tarea gestora comenzaba con la propiedad o el control de buena parte de las parcelas de olivar. Este interés directo, lo atestiguan también los datos. De las 117 parcelas documentadas, llegamos a conocer 115 propietarios, y de nuevo el colectivo artesanal textil deviene protagonista: suponen el $60 \%$ de los dueños de las parcelas según indican los notarios (Tabla I). En esta lista nos aparecen pelaires, tintoreros, sastres, tejedores y pañeros (drapers), aunque son los primeros los más interesados en la propiedad de los olivares (con casi la mitad de la nómina). Más allá del sector de la manufactura de la lana, el 30\% de los propietarios citados en los protocolos notariales son campesinos (donde los musulmanes suponen algo más de la mitad). ${ }^{13}$

13 No se nos escapa del detalle de conocer la titularidad real de las parcelas en cuestión. Si bien en número de ellas que aparecen como de propiedad alodial es muy elevado, las fuentes no siempre indican si nos 
Tabla I. Estructura socioprofesional de la propiedad en los olivares documentados Comarca el Comtat (1470-1500)

\begin{tabular}{|l|c|c|}
\hline Propietarios de olivares & Núm. & $\%$ \\
\hline Pelaires & 52 & 45,21 \\
\hline Tintoreros & 9 & 7,82 \\
\hline Sastres & 3 & 2,6 \\
\hline Tejedores & 2 & 1,73 \\
\hline Pañeros (drapers) & 2 & 1,73 \\
\hline Agricultores & 32 & 27,82 \\
\hline Mercaderes & 4 & 3,47 \\
\hline Tenderos musulmanes & 2 & 1,73 \\
\hline Caballeros & 6 & 5,21 \\
\hline Pastores & 2 & 1,73 \\
\hline Molinero & 1 & 0,86 \\
\hline TOTAL & 115 & \\
\hline
\end{tabular}

Fuente: Protocolos Guillem Peris et alii (APPV y AMC). Elaboración propia.

Esta peculiar estructura de la propiedad nos indica, en primer lugar, el interés de los sectores urbanos en este mercado de la tierra. Observamos que es en efecto el capital urbano (que surge de la manufactura y en menor medida del comercio) el que accede a estas parcelas para su aprovechamiento y gestión, contribuyendo incluso a ampliar la superficie oleícola de la comarca. En segundo lugar, esta estrategia de acercamiento al olivar se traducirá además en un intento de ir renovando las formas de conducción de la tierra mediante la implementación de sistemas de arrendamiento o aparcería. Este intento de control de los olivares buscaba en el fondo la gestión de todo el ciclo oleícola, desde su producción al consumo, y tanto en ámbito doméstico como en los talleres artesanales. Y este progresivo control de los sectores urbano-artesanales es el que propició, desde finales del siglo XIV y a lo largo de todo el XV,

encontramos ante tierras «francas» o a censo enfitéutico. No obstante, a pesar de las evidentes diferencias de una u otra forma de propiedad, entendemos que lo destacable aquí es cómo el sector artesanal pañero muestra un llamativo interés en la gestión o el control de este nuevo y estratégico cultivo. Por otro lado, en relación a la importancia de la propiedad alodial en la comarca, y del papel del colectivo mudéjar en su estructura agraria, Llibrer, 2014c. 
la superación de la autarquía en el sector oleícola para acercarlo a una economía mercantil. El control de los costes de producción del aceite (que, como hemos visto, exigía amplios aportes de mano de obra), la garantía de una producción constante, y finalmente el control de sus precios, llevó a todos esos artesanos y mercaderes a intervenir en la oleicultura.

Esta intervención se vehiculaba no sólo mediante el acceso a las parcelas, sino también con su posterior arrendamiento a grupos campesinos. Aunque no hemos documentado muchos de estos contratos, unos pocos nos permiten un interesante análisis. La prospección en las fuentes nos ha dado como resultado ocho de estos acuerdos de gestión de la tierra, y si bien parecen pocos en un arco de treinta años, lo cierto es que superan a los localizados para parcelas de cereal o moreral (un total de cinco documentados), o la viña (sólo uno). Sabemos que muchos de estos contratos, más cercanos a la aparcería asociativa, se realizaban sin pasar por el notario, de ahí su escaso número en las fuentes, no obstante, nos permiten conocer las estrategias de gestión de los olivares. En ningún caso sobrepasaban los tres años de duración, y como precio anual se establecía una parte de la producción: en ocasiones, la mitad, en otras, una cantidad nominal que iba de los 300 a los 2.500 litros. Sólo en un caso, la renta se establece en metálico (60 sueldos anuales). La formulación de estos contratos obligaba al arrendatario a la realización de todas las tareas que el cultivo necesitaba a lo largo de la temporada, y desvinculaba al propietario de tales cargas laborales. En definitiva, los artesanos cedían sus parcelas a los campesinos, y de esta forma se garantizaban un aprovisionamiento de aceite necesario para sus actividades manufactureras o para el mercado. El interés por el pago en aceite, y no en dinero, testimonia esta estrategia de gestión de unas parcelas y un cultivo tremendamente complejos.

\section{Los espacios de transformación: propiedad y gestión de los molinos de aceite}

La estrategia oleícola del grupo emprendedor local se completaba con una intensa acción en las instalaciones de transformación de la aceituna. Al igual que los olivares, las almazaras están también muy presentes en la documentación de la comarca, y su número es otro de los testimonios del cambio agrícola citado. Ya indicamos el más de medio centenar de referencias, que se han traducido en la identificación efectiva de más de una docena de estas instalaciones situadas en solo una villa, o en su entorno rural más cercano. 
De las catorce almazaras documentadas, ocho estaban ubicadas en el espacio urbano de Cocentaina; otras tres en la vecina Muro del Comtat, una en Alcoi, otra en Benimarfull, y finalmente otra en Planes, la más alejada de la capital, pero sólo a diez kilómetros de las murallas de Cocentaina. En cuanto a su propiedad o gestión, exceptuando dos casos en los que no hemos obtenido referencias, para el resto de prensas, el papel de los empresarios-artesanos del textil fue, de nuevo, determinante. Documentamos dieciocho propietarios (en todo el periodo 1470-1500), y de estos dieciocho, trece eran pelaires o pañeros vecinos de Cocentaina, mientras que dos eran mercaderes vecinos de la misma villa. Un caballero de la pequeña nobleza local, y dos agricultores, completan la nómina de gestores. De nuevo parece ser que el capital artesanal y mercantil urbano ajeno a la tierra (aunque sobre todo artesanal que, como hemos visto, no es tan ajeno a la tierra de los olivares), es el que aportaba la inversión necesaria para el mantenimiento, la gestión y el funcionamiento de estas instalaciones. De hecho, es este mismo sector emprendedor urbano el que se llegó a encargar incluso de la construcción de estas infraestructuras. ${ }^{14}$

Por lo que muestran las fuentes, la compra directa o el arrendamiento fueron las formas de acceso a estos molinos: seis documentos de compraventa y cuatro arrendamientos confirman la idea. Hay que indicar además que algunas almazaras aparecen como de propiedad franca o alodial, sin estar sometidas a censo feudal (cuatro del total de catorce). Es lógico pensar que la iniciativa privada y emprendedora de los artesanos y mercaderes empresarios comenzó a jugar un papel clave en la construcción y en la puesta en funcionamiento de muchas de estas instalaciones, sin que la autoridad feudal pusiera obstáculos al desarrollo de una actividad de la que recibía otros ingresos complementarios, como el que se derivaba de las transacciones, de los diezmos o las particiones del aceite, el iusolei. ${ }^{15}$

El mismo valor que se asignaba a las almazaras ya nos indica su trascendencia en la vida económica local. En las compraventas, la media de capital invertido era de 1.600 sueldos (con un máximo de 2.500 y un mínimo de 1.000

14 La documentación notarial nos ha aportado un ejemplo muy interesante: a principios de 1487, el mercader contestano Bernat Cirera solicitaba al mismo conde de Cocentaina el permiso para construir una almazara más en la villa de Muro, APPV, 23.812 (1487-I-3).

15 El conde de Cocentaina recibía anualmente miles y miles de litros de aceite en este concepto. En 1479 recibió 1.600 arrobas (19.400 litros) por este derecho sólo por la villa de Cocentaina, APPV, 23804 (1479-I-24). En 1490 recaudó 7.300 litros por las pequeñas alquerías de Gaianes y Torballos, que entre las dos no superaban los 40 fuegos, APPV, 23.815 (1492-I-22). Sorprendente rendimiento oleícola para comunidades rurales tan pequeñas. 
sueldos). Es cierto que los datos que aquí poseemos (sólo seis compraventas) no conforman una gran serie como para establecer cifras determinantes, pero al menos sí resultan significativas sobre la elevada inversión inicial para acceder a estas instalaciones. En el caso de los arrendamientos, los censos, generalmente en metálico, son también elevados, y van de los 120 a los 350 sueldos anuales. Si el pago se regula en especie, se establece generalmente la mitad del aceite producido o una cantidad fija (de entre 300 a 650 litros). Y, como en el caso de las parcelas de olivos, la periodización de dichos contratos no va más allá de tres años.

Todos los datos aportados nos indican que la inversión que exigía el acceso a una almazara era muy cercana a la que requería el acceso a un molino batán, a una tintorería o a un tirador de paños, como documentamos en la misma comunidad manufacturera contestana (Llibrer, 2010), y ello explica que sólo los artesanos empresarios con mayor volumen de negocio podían hacer frente al capital necesario. En realidad, las almazaras se convirtieron también en infraestructuras industriales como las citadas, necesarias para la producción textil, y por ello de estratégico control por parte de los artesanos. La instalación de la almazara con sus inmuebles no es lo único que justifica su elevado precio, sino la trascendencia del aceite en los procesos de producción manufacturera.

Cuando nos referimos a las almazaras no sólo debemos pensar en el artefacto mecánico de rulos y viga. Las fuentes nos las describen como un complejo de edificios con varios espacios necesarios a la actividad oleícola: graneros para almacenar la aceituna, patios para extenderla, depósitos para la pasta sobrante, hogar para calentar el agua del escaldado, pilas para el decantado, habitación para las grandes jarras, etc. La tipología de almazara era de molino rompedor con una o dos piedras troncocónicas, los llamados rotllos de la documentación. ${ }^{16}$ Este sistema, derivado de la mola olearia romana, estuvo en uso en la comarca, y en muchas áreas de la costa mediterránea peninsular hasta el siglo XX (Amouretti y Comet, 1985; Martínez, 1995; Cascant, 2014). La organización del proceso de producción en las almazaras descritas estaba bien delimitada en función de sus espacios: tras su traslado al molino, se depositaban las aceitunas en un almacén (graner de metre olives) formando los montones que iban pasando a la molienda para obtener una pasta triturada; posteriormente se exprimía esa pasta mediante varios prensados (y escaldando con agua caliente) para obtener una mayor cantidad de aceite (Llibrer, 2019). 
En relación con el rendimiento de estas instalaciones, y con las cantidades que podían generar por jornada, disponemos de escasa información local; no obstante, un pequeño dato comparativo, de la vecina Murcia, y para almazaras técnicamente similares, nos permite hablar de una capacidad de producción diaria de entre 8 a 14 arrobas, es decir, entre unos 90 a 160 litros (MartínConsuegra, 2001: 155). Así, calculando con estas sencillas cifras, las catorce almazaras documentadas en nuestra comarca, en pleno proceso de molturación allá por los meses de enero y febrero, podrían poner en el mercado diariamente unos 1.700 litros. La cantidad, que nace de un relativo análisis comparado, nos sirve al menos para indicar que la producción contestana tuvo un destino que iba mucho más allá de las necesidades domésticas de los vecinos, y un objetivo claramente merceológico en función de la demanda de la industria textil y de un mercado supracomarcal en desarrollo.

A su vez, si al dato anterior le aplicamos el índice de rendimiento de la aceituna en época bajomedieval, de entre el 15-20\%, podemos llegar a calcular que para producir esos 1.700 litros diarios eran necesarios unos 10.000 kilos de aceituna. ${ }^{17}$ Es así fácil adivinar la frenética actividad que, desde diciembre hasta más allá de febrero, se llevaría a cabo tanto en las parcelas de olivar como en las almazaras. El impacto sobre la economía rural y también la urbana era sin duda trascendental, llegando a condicionar en estos meses el trabajo de muchos activos de la comarca.

\section{El mercado de aceite y sus operadores económicos}

Sabemos que entre 1470-1500 en la ciudad de Cocentaina llegaron a trabajar de forma simultánea hasta cinco notarios, lo que nos indica, por un lado, el carácter de capitalidad que adquirió este núcleo, que atraía iniciativas de su activo espacio rural pero también de villas de otras comarcas vecinas; a su vez, nos habla de la multiplicidad de transacciones y negocios que demandaban la escrituración de sus actos. ${ }^{18}$ No obstante, la limitada conservación de todo este amplio bagaje documental, con la supervivencia de los libros de un solo notario (y no completos), junto a unos pocos volúmenes sueltos de otros, nos dificultan la reconstrucción con detalle de actividades, negocios y empre-

17 Los índices de rendimiento del cultivo en época bajomedieval han sido calculados y justificados por Pinto, 2002: 131, y Cortonesi, 2005: 14.

18 Analizamos ya esta interesante relación entre escrituración y negocios, en Llibrer, 2013 a. 
sas. Aún así, lo que nos ha llegado permite al menos la concreción de tendencias y procesos. Esto mismo nos ocurre con el mercado del aceite: a pesar de haber localizado poco más de doscientas transacciones (216) para un periodo de treinta años, su valor es de enorme trascendencia, tanto por lo que nos aportan y nos dicen, como por lo que silencian. Pensemos, en primer lugar, que hablamos de la información que nos aporta un solo notario de los cinco presentes en la villa; no olvidemos, además, que sólo un pequeño porcentaje de compraventas de estos productos locales pasaba por la mesa notarial a causa del coste que la redacción del documento y de sus copias suponía para ambos clientes, comprador y vendedor. ${ }^{19}$ Aunque no podemos calcular qué porcentaje de este mercado quedaba fuera del registro notarial, lo que resulta evidente es que la actividad oleícola de la comarca sería mucho mayor a la que nos aparece en las cuartillas de los protocolos, y que un innumerable conjunto de pequeñas o medianas compraventas se llevaban a cabo entre vecinos de la comarca sin mediación administrativa alguna.

Las más de doscientas compraventas documentadas nos permiten, a su vez, un detallado análisis de los operadores y de las prácticas mercantiles. El colectivo que de forma destacada se encargaba de la distribución de aceite en la comarca era de nuevo el de los pañeros. El 62,5\% de los vendedores eran artesanos, sobre todo pelaires (que suponían el $40 \%$ de los distribuidores). Muchos de estos pelaires actuaron, en efecto, como auténticos «señores del paño», auténticos empresarios que mediante la adquisición de las materias primas (lana, aceite y tintes) activaban el proceso de producción y gestionaban sus numerosas fases de elaboración, incluso el abatanado y el tintado. En Cocentaina se han localizado numerosos casos de estos emprendedores que fueron también los gestores del mercado de aceite y de las propias almazaras (Llibrer, 2015). Si a estos pelaires y pañeros sumamos un reducido grupo de tintoreros y sederos, llegamos a confirmar cómo el $62,48 \%$ de los distribuidores de esta comarca aceitunera tenían su origen en la industria de la lana.

A su vez, es importante destacar que los mercaderes profesionales (ajenos al sector manufacturero) sólo aparecen en el 17,85\% de las ventas, lo que nos confirma la función clave del capital artesanal en la producción y venta del aceite. Eran los pelaires (y otros artesanos textiles) los que gestionaban la

19 Es convincente pensar que sólo cuando el negocio o la operación era de cierta entidad económica, o cuando el vendedor tenía dudas de la solvencia del comprador, se decidía el paso por la oficina del notario. 
producción de las parcelas, la transformación de la aceituna en las almazaras, y su venta posterior. Y esto se confirma también por el hecho que los agricultores de la comarca intervienen pocoen la transformación y venta del aceite (sólo aparecen en el 12,45\% de las ventas). En el grupo de los agricultores hay que destacar a algunos miembros del colectivo mudéjar $(7,14 \%)$, pertenecientes a importantes familias islámicas de la comarca, que redistribuyen aceite en pequeñas cantidades entre los vecinos de las numerosas aljamas del área. ${ }^{20} \mathrm{La}$ nómina de vendedores de aceite se completa con unos pocos jaboneros, cuatro caballeros de la pequeña nobleza local y un notario.

Por otro lado, en relación con los colectivos que adquieren el aceite que preferentemente los artesanos del textil ponen en circulación, eran los agricultores de la comarca y de zonas vecinas los compradores más destacados, conformando un $65 \%$ de la nómina general. Entre estos debemos resaltar la importancia de los mudéjares (el 44\%), que poblaban las sierras y valles del interior de la comarca (Seta, Gorga, Travadell, Mariola, Benicadell, Gallinera, Guadalest), y que acudían a la capital para el abastecimiento de bienes de consumo básicos (Llibrer, 2014 c).

Pero no debemos olvidar que los menestrales del textil, y esencialmente los pelaires, vuelven a ser protagonistas también de las adquisiciones, completando un $20 \%$ de los compradores. Un grupo de jaboneros $(3,17 \%)$ nos confirma que el aceite como materia prima industrial vuelve a estar presente en la función económica de este mercado. En relación a los profesionales del comercio, hay que resaltar también su limitada presencia, sólo el 7,93\%, donde predominan los minoristas (tenderos y trajineros) que distribuían entre vecinos de la comarca. Es decir, los grandes mercaderes de la zona tampoco adquirieron aceite en grandes cantidades para después distribuir, sino que eran directamente los artesanos del textil los encargados de la gestión del mercado oleícola, de la misma manera que lo eran del mercado de la lana o de los productos para el tinte (Llibrer 2010, 2015).

Pero para evaluar correctamente las características de este mercado y su función económica es necesario explicar el volumen de las transacciones y su metodología. En este sentido, debemos indicar que la compra media de aceite contestano era de 54,34 arrobas, lo que supone la elevada cantidad de 660 litros. La venta más elevada en una misma transacción es de 600 arrobas (7.284

20 Ya estudiamos estos operadores de las aljamas en Llibrer 2014c. 
litros), y la menor de 6 arrobas (73 litros). ${ }^{21}$ Por otro lado el 15\% de las compraventas notariales sobrepasaban el centenar de arrobas (más de mil litros); ambos datos (la cifra media, 660 litros, y esta última) nos confirman que estas adquisiciones de aceite tenían en muchos casos una finalidad profesional o industrial que la alejaba del simple consumo doméstico asociado a la alimentación. Las inversiones necesarias para poder adquirir este producto corroboran esta finalidad.

Como analizamos un mercado en un arco cronológico muy ajustado (los treinta años que van de 1470 a 1500) y en un ámbito geográfico-comarcal también muy preciso, podemos valorar los precios de la forma adecuada sin caer en amplios desajustes o devaluaciones que podrían distorsionar las conclusiones. Como es lógico, el precio del aceite fluctuaba a lo largo del año en función del ciclo agrario del olivar y de su recolección, por ello es frecuente encontrar cifras con importantes diferencias (Tabla II). En nuestro mercado contestano, su precio va de los 4,5 hasta los 11 sueldos por arroba, en función tanto del período de adquisición como del tipo de compra, ya que en numerosos casos documentamos transacciones anticipadas, previas a la recolección y al prensado de la aceituna. Era una estrategia de muchos compradores para garantizarse importantes cantidades de aceite necesarias para su negocio, y ya Melis habló de ella en relación a los empresarios textiles toscanos (Melis, 1972: 130). Y era precisamente cuando se realizaban estas adquisiciones anticipadas (en los meses de septiembre, octubre y noviembre, y que llegan a suponer el $21,42 \%$ del total de compraventas), cuando el precio solía ser más ajustado, entre los 4,5 y 5 sueldos por arroba. Es evidente que la compra anticipaba generaba un riesgo en el comprador, era una auténtica compra a crédito, ya que debía adelantar el precio del producto, pero no lo recibiría hasta meses después (normalmente en febrero, como nos indican los contratos conservados) y de ahí la necesidad de establecer unos precios más ajustados.

21 Como indicábamos más arriba, se produjeron sin duda innumerables ventas en menores cantidades, pero no solían pasar por la mesa notarial, lo que dificulta el conocimiento de este comercio minorista. No obstante, en los registros del Justicia local se encuentran testimonios de este activo mercado de detalle. Entre 1456 y 1458, los oficiales contestanos anotaron un total de diez denuncias por aceite, con una media muy limitada de 15,5 arrobas por venta. Y en seis de estas denuncias, la cantidad de aceite no sobrepasaba las 4 arrobas, AMC, Cort de Justícia, 153 y 154. Los impuestos de la sisa de las villas valencianas son también un interesante testimonio de la presencia de este comercio oleícola: Guinot y Mira, 2008: 153. 
Tabla II. Variación anual del precio del aceite.

Comarca El Comtat (1470-1500)

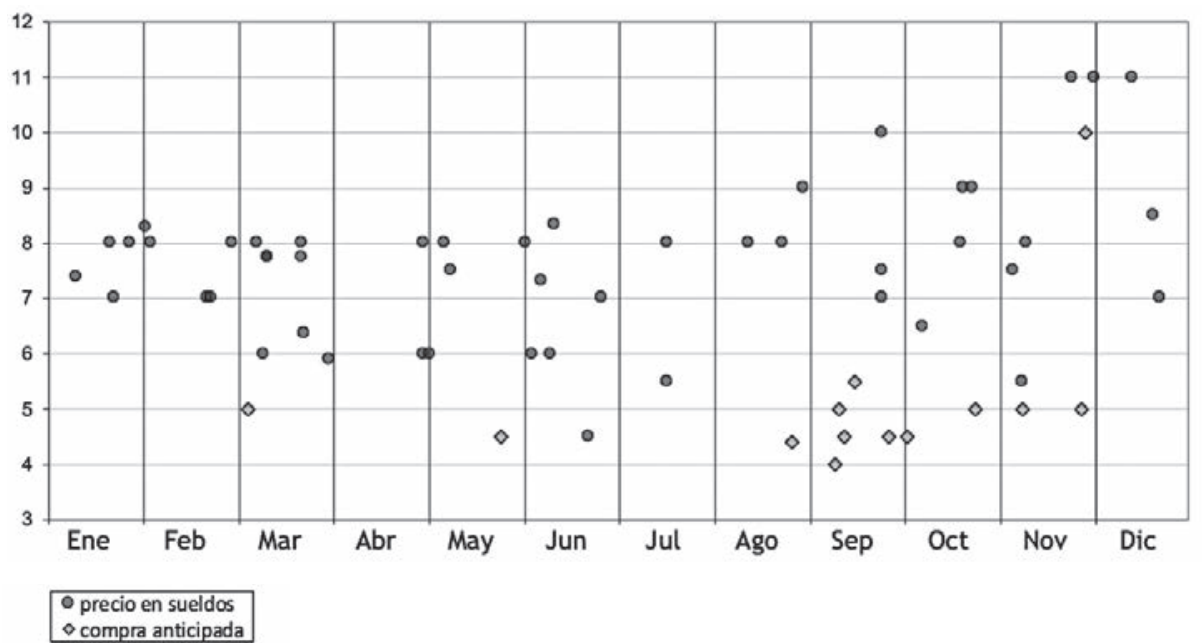

Fuente: notario Guillem Peris y otros. Elaboración propia

Las cifras más altas del valor del aceite (entre 10 y 11 sueldos) se documentan en el periodo anual en que el producto de la temporada comienza a escasear, de septiembre a diciembre. El inicio de la limitación de la oferta contribuye, como es lógico, a un aumento de los precios, por ello es en estos mismos meses cuando algunos operadores comienzan ya a comprar anticipadamente el aceite que se elaborará la temporada siguiente. En los meses centrales del año, de febrero a agosto, el precio se sitúa entre los 6 y 8 sueldos, como corresponde a este periodo en el que su oferta es todavía elevada tras la recolección. Estas fluctuaciones en el precio no hacen sino indicarnos el carácter y el objetivo merceológico que tenía el aceite en la comarca y que se había alejado ya del marco autárquico tan presente aún en buena parte del reino.

Con este conjunto de precios, se deduce que la inversión media realizada en el mercado contestano para la adquisición de aceite era de unos 422 sueldos; sin embargo, atendiendo al conjunto de las 216 compraventas documentadas, observamos que el $65,85 \%$ del aceite comercializado sobrepasaba el precio de 6 sueldos, por lo que la inversión media para la compra sería prácticamente de unos 500 sueldos; cantidades que, en uno u otro caso, eran cierta- 
mente elevadas. Estamos, por tanto, ante un mercado mayorista, con un volumen en circulación muy alto, fruto evidentemente de la elevada capacidad productiva de la comarca. Sin un nivel de producción adecuado la comercialización hubiera sido simplemente al por menor, en compraventas de pequeñas cantidades, como las que hemos visto en los libros judiciales (de menos de 10 arrobas), y como ocurre en buena parte de las áreas rurales valencianas. Pero aquí, la producción en aumento generó a lo largo de los treinta años analizados un volumen de negocio oleícola extraordinario, y casi único en el contexto bajomedieval de la Corona de Aragón.

Si bien el aceite que está presente en todo este activo mercado tiene su origen en la misma comarca del Comtat, podemos concretar aún más su producción en la zona periurbana, asociada al ritmo y a la iniciativa económica de la capital (Muro, l'Alcúdia, Almudaina, Benimarfull, Planes o Fraga). No obstante, el aceite se distribuía con mucha frecuencia más allá de los límites de esta comarca. La nómina de compradores del producto nos permite dibujar un amplio mapa supracomarcal por el que circulaba el preciado aceite contestano. Bocairent, Biar, Castalla, Onil, pero también Pego, Alacant o Elx, configuran un mercado regional con un círculo de acción de casi $100 \mathrm{~km}$, si tomamos como referencia la villa de Cocentaina, auténtica base de los negocios aceiteros de la comarca, y donde residían los más importantes y activos empresarios oleícolas. Pero la articulación del mercado contestano del aceite es mucho más compleja de lo que muestran estas cifras generales. De hecho, este mercado se estructuraba en función de tres áreas o círculos de acción bien diferenciados: por un lado estaba el destino local, ya que buena parte de la producción era dedicada a abastecer a la importante comunidad artesanal pañera de la villa de Cocentaina y su comarca; en segundo lugar, la documentación nos muestra que otra parte del aceite contestano se comercializaba en las comarcas vecinas de l'Alcoià o la Valld'Albaida, y circulaba hacia comunidades o villas como Bocairent, Onil, Castalla o Biar, configurándose así un segundo anillo del mercado contestano con un radio de acción de entre unos 20 a 30 km; en tercer lugar, el aceite del Comtat llegaba a comercializarse en villas o ciudades situadas entre los 40 y los $80 \mathrm{~km}$, y tanto hacia el norte y la costa, como era el caso de Pego, o hacia el sur en dirección a Alicante o Elx, lo que dibujaba una interesante demanda oleícola para los empresarios contestanos. ${ }^{22}$ 
De todos modos, sería interesante conocer qué parte, qué cantidad de la producción contestana era «exportada», es decir, qué porcentaje salía hacia estos mercados supracomarcales. Las numerosas compraventas documentadas nos indican que hasta el $25 \%$ del aceite comercializado circulaba en dirección a esos dos círculos exteriores, dato nada desdeñable que nos llega a confirmar dos ideas clave: por un lado, la importante capacidad de producción oleícola contestana, que permitía a la vez abastecer tres tipos de demandas distintas (la doméstica local, la que generaba la amplia manufactura textil de la comarca y la que originaba una demanda exterior ya de cierta intensidad durante el último tercio del siglo XV); pero por otro lado, las cifras de este mercado nos indican además la interesante vocación mercantil que desde muy pronto desarrollaron los artesanos-empresarios contestanos, ya que eran ellos los que de forma directa (y sin otros intermediarios) ponían en circulación este aceite que sobrepasaba los límites de la comarca, respondiendo ya así a los estímulos del mercado. Es decir, este sector emprendedor local vio y entendió las posibilidades que el aceite tenía como producto merceológico que podía generar destacados beneficios. Una vocación oleícola mercantil que se iniciará en estas décadas finales del Cuatrocientos, pero que se convertirá ya en una constante posterior para la vida económica contestana (Cabrera González, 1986; Peris, 1995: 486-487; Torró, 2005; Cascant, 2014).

Lógicamente era necesario coordinar toda esta iniciativa económica, coordinar y gestionar todo este esfuerzo productivo, la gran cantidad de mano de obra implicada, las instalaciones, la maquinaria, el transporte, las inversiones necesarias. Todo lo analizado anteriormente nos ha descubierto ya la presencia y la acción de un destacado grupo de emprendedores oleícolas, de auténticos empresarios que, por necesidad artesanal, vieron en el aceite una materia prima básica, pero también una interesante oportunidad de negocio y de mercado para un producto con una demanda en aumento. Así, la necesidad de garantizarse un suministro de aceite necesario a su trabajo textil de la pelairía, los llevó a acercarse a las fases y los espacios de producción oleícola: accedieron a la tierra adquiriendo parcelas de olivar y contribuyendo a su extensión; contactaron con campesinos para mantener estas parcelas; se interesaron por adquirir y controlar las almazaras para gestionar la moltura; incluso decidieron acceder al mercado para vender ese aceite que era cada vez más cotizado.

Conocemos bien el perfil social y económico de estos emprendedores gracias a los análisis prosopográficos que hemos realizado en el espacio contestano (Llibrer, 2010). Prácticamente todos venían del mundo de la manufactu- 
ra, y más en concreto del sector de la pelairía, que suponía el control de las tareas de tratamiento inicial de la lana, y de las fases de acabado del paño - el tundido, el abatanado y en ocasiones incluso el tintado (Llibrer, 2014b). La dedicación y la gestión de estas operaciones manufactureras por parte de estos artesanos empresarios implicaban, por un lado, el control de las instalaciones industriales donde se llevaban a cabo (los molinos batanes, las tintorerías, los tiradores de paños, las almazaras); y, por otro lado, la participación de forma directa en el mercado de las materias primas, comprando y distribuyendo lanas, tintes y aceite entre artesanos de estas villas y comarcas. La producción y venta de aceite era una más de las estrategias empresariales de estos operadores, de la misma forma que la propiedad de otros inmuebles rústicos o de amplias cabañas de ganado lanar. El acceso al aceite fue para ellos un negocio necesario y complementario.

Enunciaremos sólo unos pocos casos de estos emprendedores oleícolas que nos servirán para confirmar su perfil social y sus líneas de negocio. El primer caso destacable es el de Gabriel Bosch, pelaire (panniparator contestano), que poseyó al menos cuatro inmuebles en la villa: dos casas, una con corral, un taller y una almazara de producir cera. Tuvo una cabaña de más de 200 cabezas de ganado ovino. Además, fue propietario de cuatro parcelas (una de cereal, dos de viña y una de moreras, y todas ellas alodiales). Pero lo más destacado en su patrimonio fundiario es que fue el señor de la alquería de Ares, en término de Penáguila, donde se abastecía del aceite necesario para sus negocios y donde contaba con una almazara. De hecho, su dedicación al comercio de aceite fue intensa. Un ejemplo: en sólo nueves días de marzo de 1482, vendió 1.700 litros a ocho diferentes vecinos de Pego (a $30 \mathrm{~km}$ ), y consiguió unos ingresos de 1.350 sueldos. Su mercado se amplió en años posteriores: realizó ventas a un mercader de Elx (a unos $70 \mathrm{~km}$ ) con medias de más de 4.000 litros, y para ello contactó con un trajinero musulmán que realizase el transporte. Fue, además, el recaudador del «derecho del aceite» del conde de Cocentina, y tomó en arrendamiento el derecho del peso, dret del pes. Su relevancia en la vida municipales amplia pues desempeñó prácticamente todos los cargos de las magistraturas urbanas: justicia en 1481, jurado en 1491, 1498 y 1502, y almotacén en 1493. Casó a su hija con el más activo tintorero de la villa y le concedió una elevada dote de 9.000 sueldos. $^{23}$ 
Otro interesante ejemplo es el de Joan d'Estanya, pelaire que evolucionó a pañero (draper), y a quien encontramos vendiendo lana, paños, ganado, cereales y, sobre todo, aceite. Poseyó al menos un olivar y también una heredad franca en Muro en zona de regadío. Fue señor de la alquería de Benifloret, en la que tenía residiendo al menos a dos familias islámicas que se encargaban de la explotación de sus olivares. Fue propietario, además, de una almazara alodial, en Cocentaina, que compró en 1471 por 1.000 sueldos. Le documentamos más de una decena de ventas de aceite (con una media por transacción de 34 arrobas, 420 litros). Fue jurado (1470 y 1473) y justicia local (1481). Hizo donación a su hijo — por matrimonio con la hija de otro importante pelaire vecino-, de 12.000 sueldos (en metálico y censales). Su hijo continuó los negocios mercantiles de la empresa paterna: compra de lana, venta de paños, ganado y también aceite, y en grandes cantidades (más de 2.000 litros). La familia d'Estanya tuvo especial dedicación al aceite. Otro miembro, Bernat, también pañero — que llegó a conseguir la condición de caballero (miles)—, adquirió parte de otra almazara en Cocentaina, por 1.100 sueldos, para transformar toda la aceituna producida en sus cinco heredades de Muro; de hecho, en dos años, hubo de ampliar la almazara y para ello compró un inmueble colindante.

Otra familia de pañeros que destacó por su actividad oleícola fue la de los Maiques. El padre, Bartomeu (1471-1496), adquirió un amplio patrimonio fundiario: siete parcelas (cuatro de cereal, una viña y dos olivares), pero también una alquería en el término de Cocentina, explotada por varias familias musulmanas. Vendía aceite, pero también lo compraba de forma anticipada, sin duda para redistribuirlo condiciones ventajosas. Su hijo Bartomeu (1480$1500)$, un pelaire que se reconvirtió en mercader (mercator), vendió aceite (650 litros de media) y también cereales y paños. Pero su interés por el aceite fue mayor ya que amplió el patrimonio oleícola con dos parcelas más de olivar y con una almazara con corral contiguo. Fue, además, hombre de confianza del conde de Cocentaina y gestionó durante años su administración.

El pelaire Bernat Martí (1470-1482) aparece como uno de los comerciantes de aceite más activos. Compraba y vendía lana y paños con frecuencia, lo que nos habla de su elevada producción textil. Gestionó, además, el tintado de los paños mediante acuerdos o compañías con tintoreros vecinos (Llibrer 2014b). Comercializó cereales, vino y aceite en grandes cantidades. Su estrategia parece estar en comprar anticipadamente el producto para después venderlo en condiciones ventajosas: entre agosto y noviembre se reservaba y pa- 
gaba el aceite en grandes cantidades (siempre más de 2.000 litros y a un precio de 4,5 sueldos por arroba), con inversiones superiores al millar de sueldos pagados de forma anticipada, lo que denota su capacidad de inversión; los productores se comprometían a llevarle el aceite a su casa (sin duda con gran capacidad de almacenaje) durante los meses de enero a marzo; posteriormente Bernat fue vendiéndolo en transacciones con una media de 770 litros. En sólo un día (11 de noviembre de 1479, periodo de escasez de aceite justo antes de la nueva cosecha) llegó a vender 4.100 litros en cuatro operaciones, y en un mes logró distribuir más de 6.000 litros. Hemos calculado, en función de los precios de compra y los de las ventas (que siempre sobrepasaban los 8 sueldos, es decir el doble del valor de adquisición) que los beneficios que este juego con la demanda le generaban anualmente, superaron los 3.000 sueldos.

La familia Ripoll fue otra de las interesadas en el negocio oleícola. El padre, Francesc, pelaire (1471-1488), ya era propietario de una gran almazara, la del Pla de la Font. Uno de sus hijos, Antoni, también panniparator (14821500 ), adquirió otra almazara y una heredad formada por varias parcelas y establo. Vendía aceite con una media de unas 90 arrobas (casi 1.100 litros) y adquirió la mitad de un molino harinero. Su hermano Bernat, pelaire y pañero (1480-1502), compró dos parcelas de olivar y recibió en herencia la almazara de su padre, que posteriormente fue dividida en dos en una interesante estrategia empresarial: una parte la vendió por 1.100 sueldos y la otra la arrendó mediante contratos de corta duración (un año) y a cambio de censos en especie que siempre sobrepasaron los 600 litros.

La lista de estos emprendedores interesados en el aceite podría continuarse con algunos ejemplos más de la misma villa, pero el perfil nos ha quedado fijado ya con varias características comunes: el origen de su negocio y de su interés por el aceite nace del mundo artesanal, de la producción y venta de lanas y paños; posteriormente, su capacidad inversora se dirige hacia la tierra para adquirir heredades o parcelas de olivar; el intenso trabajo de este cultivo y su recolección se realizaba mediante mano de obra asalariada, o a través de contratos de arrendamiento; el trabajo en la almazara era gestionado por estos artesanos de la misma forma, mediante asalariados, mozos o aprendices de taller que aparecen con frecuencia en los obradores textiles; finalmente, el conocimiento del mercado que estos menestrales tenían, gracias a la venta de lanas y paños, les propició la oportunidad de distribuir también el aceite de sus almazaras o el que compraban de forma anticipada a precios más bajos (Llibrer 2010, 2014b). 
En definitiva, y no podemos olvidarlo, hablamos de una producción y venta de aceite activada y gestionada por artesanos del textil, no mercaderes profesionales o por ricos agricultores, sino por un sector emprendedor de la pañería que cada vez derivaba más sus negocios hacia las oportunidades que le ofrecía la demanda de este cotizado producto.

\section{Conclusiones}

Para acercarnos al estudio de la producción oleícola y a sus usos industriales necesitábamos una visión intensiva, centrada en un espacio geográfico muy concreto, pero que ofrecía interesantes datos de inicio. En efecto, entre el volumen documental de esta zona se dejaban entrever una serie de tendencias que, tras el tratamiento y la interpretación en profundidad de los datos, han permitido una imagen de conjunto sobre un proceso económico de consolidación sectorial.

La importancia y el desarrollo de la industria textil implementaba este proceso, y sus propios operadores ya nos aparecían como gestores del mismo. En el fondo, nos encontrábamos ante un fenómeno que se había concretado - y se estaba concretando-, en otras áreas de la Corona de Aragón: nos referimos a la penetración o inversión del capital urbano en las zonas rurales para complementar y finalizar negocios (Iradiel, 1999, 2003, Sesma, 1992, 2005). En nuestro caso, esta inversión se materializó en un progresivo esfuerzo por impulsar la producción lanera con la gestión de grandes cabañas de ganado, por activar la obtención de productos para el tinte y, también, —y éste es aquí un factor diferencial — por desarrollar y aumentar la olivicultura. Se fueron así estableciendo múltiples y complejos intercambios entre los intereses urbanos, o artesanales en nuestro caso, y los de las áreas rurales circundantes. Estos intercambios no sólo implicaron la inversión para la adquisición de tierras, sino también la implantación de una nueva «cultura del olivo». Esta «cultura del olivo» no refería únicamente a la idea de extensión física del cultivo en más y más parcelas, sino a la idea de llegar a ejercer sobre la economía campesina, sobre las familias campesinas, una influencia o un importante cambio de mentalidad para que aceptaran esta nueva propuesta económica, para que una buena parte de su esfuerzo laboral se centrara en este nuevo cultivo, que además exigía trabajo intenso en determinados periodos; $y$ también para que llegaran a entender que el olivo no era un cultivo marginal dedicado al autoconsumo y comprendieran su potencialidad, sus posibilidades y los estímulos que generaba en el mercado. 
Por todo ello hablamos de un complejo proceso de especialización que se fue gestando a lo largo de todo el siglo XV, y que es ya perceptible con datos documentales en su segunda mitad. Aquí destaca el papel que los emprendedores oleícolas desarrollaron. Estos llegaron a desempeñar una triple función económica: en primer lugar, de coordinación y gestión de las explotaciones olivareras (en ocasiones hasta de su misma configuración); en segundo lugar, de control de los procesos de transformación en los molinos de aceite (punto trascendental que condicionaba costes y precios); $y$, finalmente, de contacto con el mercado para la distribución y venta a una demanda exterior, sin apenas presencia de mercaderes intermediarios ajenos al proceso de producción.

Hasta tal punto la función de este grupo emprendedor fue tal que debemos hablar incluso de cierta tendencia a la concentración tanto de las explotaciones oleícolas como de los medios de producción, hasta configurar un sector aceitero de enormes posibilidades. Además, el comercio del aceite manifestaba abiertamente el conocimiento de la demanda, de los resortes del mercado y de sus posibilidades. Comprar anticipadamente, antes de que se produjera la cosecha (y avanzar el capital, mediante auténticas compras a crédito), para vender después en periodos de carestía y de presión de la demanda, muestra la comprensión de una realidad mercantil y la percepción especulativa de este nuevo producto, el aceite.

El mismo paisaje rural se fue moldeando poco a poco en función de los intereses de estos aceiteros, mientras las familias campesinas asumían la nueva disciplina productiva. Y así, más allá de una cultura promiscua, donde el olivo resultaba un complemento a las rentables parcelas de viña o cereal, los olivares fueron ocupando sucesivamente el protagonismo en parcelas, campos y heredades.

\section{Referencias bibliográficas}

Amouretti, Marie-Claire y Georges Comet(1985), Le livre de l'olivier. Aix: Édisud. BENASSAR, Bartolomé (2001), La España del siglo de Oro. Barcelona, Crítica.

BOLENS, Lucie (1991), «Al-Andalus: la vigne et l'olivier, un secteur de pointe (XI⿳亠े⿵冂⿰⿱丶㇀⿱㇒丶亅㇒-丶 XIII ̀̀ siècles)». La Production du vin et de l'huile en Méditerranée de l'Age du Bronze à la fin du XVì̀ siècle. Aix: 257-268.

BolENs, Lucie (1996), «Riquezas de la tierra andaluza y primacía del aceite de oliva en la sociedad y la civilización de al-Andalus (siglos X-XVI)», Agricultura y sociedad, 80-81: 181-216.

BORRERO, Mercedes (1983), El mundo rural sevillano en el siglo XX: Aljarafe y Ribera. Sevilla, Universidad de Sevilla. 
BRUGNOLI, Andrea y Gian Maria VARANINI (2006), Olivie olio nel medioevo italiano. Bolonia, CLUEB.

CASCANT I JORDÀ, Josep Vicent (2014), «El lèxic de l'olivera, l'oliva i l'oli al Comtat», Alberri, 24: 123-221.

CherubinI, Giovanni (1996), «Olio, olivo, olivicultori». En L'Italia rurale del basso medievo. Bari: 175-194.

CisCAR PAllaréS, Eduardo (1997), La Valldigna, siglos XVI y XVII. Cambio y continuidad en el campo valenciano. Valencia, Diputación.

ColÁs, Gregorio (2015), «Olivos y aceite en Aragón en la Edad Moderna», Chronica Nova, 41: 71-98.

COLlANTES DE TERÁN, Antonio (1994), «Mercaderes genoveses, aristocracia sevillana y comercio del aceite en el siglo XV». En Tra Siviglia e Génova. Notaio, documento e comercio nell'età colombiana. Milán: 247-359.

COLlantes de TERÁn, Antonio (1996), «Notas sobre el comercio del aceite sevillano en la baja Edad Media». En L'ouvrier, l'Espagne, la Bourgogne et la vie provinciale parcours d'un historien. Madrid: 153-160.

Collantes DE TERÁn, Antonio (2002), «La élite financiera en la Sevilla bajomedieval: los mayordomos del concejo». Revista d'Història Medieval, 11: 13-39.

COMET, Georges (1991). «Le vin et l'huile en Provencemédiévale, essai de bilan». En La production du vin et de l'huile en Méditerranée de l'Age du Bronze à la fin du XVI ${ }^{\text {ème }}$ siècle. Aix: 199-201.

CÓRDOBA DE LA LlAVE, Ricardo (1988), «Aceñas, tahonas y almazaras. Técnicas industriales y procesos productivos del sector agroalimentario en la Córdoba del siglo XV», Hispania, 48/170: 827-874.

CóRDOBA DE LA LlAVE, Ricardo (2017), Los oficios medievales. Tecnología, producción, trabajo. Madrid, Síntesis.

CORTONESI, Alfio (2002), «Vinificacione e oleificazione nell'Italia medievale». $\mathrm{Ca}$ hier d'Histoire des Techniques, 5: 143-160.

CORTONESI, Alfio (2005), «L'olivo nell'Italia medievale». Reti medievali. 4: 3-30.

Domingo, Concepción (1977), «La agricultura de Castellón de la Plana en 1468», Saitabi, 27: 221-238.

FURIÓ, Antoni Y Antonio MIRA 2005), «Le marché de la terre dans le Pays de Valence au bas Moyen Âge». En Laurent Feller y Chris Wickham (dirs.), Le marché de la terre au Moyen Âge. Roma, École Française de Rome: 573-623.

GAMERo RoJAS, Mercedes (2015), «Notas sobre la evolución del olivar en la Andalucía moderna», Chronica Nova, 41: 13-38.

GARCÍA DE CORTÁZAR, José Ángel (1988), La sociedad rural en la España Medieval. Madrid, Siglo XXI.

GARCÍA SÁNCHEZ, Expiración (1996), «El consumo del aceite de oliva y otras grasas vegetales en al-Andalus». En María Barceló, (coord.), La Mediterrània, àrea de convergència de sistemes alimentaris (segles V-XVIII). Mallorca, IEB: 15-38. 
GARCÍA SANZ, Ángel y Jesús SANZ (1998), «Agricultura y ganadería». En Miguel Artola (dir.), Enciclopedia de Historia de España. vol. I, Madrid, Alianza: 11-104. GONZÁlez ARCE, José Damián (2012), «Los beneficiarios de la fiscalidad medieval: el caso del diezmo del aceite del almojarifazgo de Sevilla en el siglo XV». Medievalismo, 22: 99-137.

GONZÁlEZ ARCE, José Damián (2015), «La producción oleícola del Aljarafe según el diezmo del almojarifazgo de Sevilla (siglo XV)». Historia agraria, 65: 43-74.

GUINOT, Enric y Antonio MIRA (2008), «Fiscalidad urbana y distribución y consumo de la producción agrícola en Valencia (siglos XIV-XV)». En Rafael Vallejo Pousada (ed.), Los tributos de la tierra. Fiscalidad y agricultura en España (siglos XII-XX). Valencia, PUV: 137-163

GUIRAL, Jacqueline (1989), Valencia, puerto mediterráneo en el siglo XV (1401-1525). Valencia, IVEI.

IGUAL, David (1995), «La ciudad de Valencia y los toscanos en el Mediterráneo del siglo XV», Revista d'Història Medieval, 6: 79-110.

IRADIEL, Paulino (1974), Evolución de la industria textil castellana en los siglos XIIIXVI. Factores de desarrollo, organización y costes de la producción manufacturera en Cuenca, Salamanca: Universidad.

IRADIEL, Paulino (1989), «La crisis medieval». En Historia de España, IV. Barcelona, Planeta: 9-29.

IRADIEL, Paulino (1999), «Ciudades, comercio y economía artesana». En XXV Semana de Estudios Medievales, Pamplona: 603-658.

IRADIEL, Paulino (2003), «Metrópolis y hombres de negocio». En XIX Semana de Estudios Medievales, Pamplona: 277-310.

Le Roy LAdURIE, Emmanuel (1966), Les paysans de Languedoc. París, SEVPEN.

LLIBRER, Antoni (1996), Godella, una comunidad rural en la baja Edad Media. Valencia, Ajuntament de Godella.

LLIBRER, Antoni (2003), El finestral gòtic. L'església i el poble de Llíria als segles medievals. Valencia: Ajuntament de Llíria.

LLIBRER, Antoni (2010), Industria textil y crecimiento regional: la Vall d'Albaida y el Comtat durante el siglo $X V$. Tesis doctoral: Universitat de València.

LLIBRER, Antoni (2012), «La gestió dels batans i el desenvolupament de la industria tèxtil al segle XV. El cas de l'àrea Alcoi-Cocentaina», Estudis d'Història Agrària, 23: 231-248.

LLIBRER, Antoni (2013a), «El notari Guillem Peris i la seua especialització artesanal: el réflex d'una societat en transformació al segle XV», Estudis Històrics i Documents dels arxius de protocols, 31: 117-145.

LLIBRER, Antoni (2013b), «La configuración d'un districte industrial a la baixa Edad Mitjana. Les viles draperes de la Vall d'Albaida, l'Alcoià i el Comtat», Recerques: Història, Economia, Cultura, 64: 5-31. 
LLIBRER, Antoni (2014b), «Artesanos emprendedores en la industria textil. Del taller al mercado: el caso del pelaire contestano Bernat Martí (1469-1482)», En la España Medieval, 37: 295-317.

LLIBRER, Antoni (2014c), «Dualidad en la aljama. Propietarios de tierra y hombres de negocio musulmanes. El caso de la comarca valenciana de El Comtat (segunda mitad del siglo XV)», Anaquel de Estudios Árabes, 25: 45-75.

LLIBRER, Antoni (2015), «Llana, ramat i oli. Empreses en època medieval: nivell d'inversió i costos a la draperia (el Comtat al segle XV)», Saitabi, 65: 63-79.

LLIBRER, Antoni (2019), «L'inici de la vocació oleícola valenciana en época baixmedieval. Producció, comerç i tecnologia», Afers, fulls de recerca i pensament, 94: 713-744.

MARTíN-CONSUEGRA, Ginés (2001), «Aproximación a la historia de la producción de aceite en la ciudad de Mula. Aportación para el estudio de las almazaras», Revista murciana de antropología, 7: 147-166.

MARTíNEZ GUTIÉRREZ, Emilio (2004), La organización del paisaje rural durante la baja Edad Media: el ejemplo de Jerez de la Frontera. Sevilla, Universidad de Sevilla.

MARTíneZ MARTíneZ, María (1995), La cultura del aceite en Murcia (siglos XII-XV). Murcia, Universidad de Murcia.

MELIS, Federigo (1972), «Note sulle vicende storiche dell'olio d'oliva (s. XIV-XVI)», En Dell'olivo e della sua cultura. Firenze, Cassa di Risparmio: 11-21.

Naso, Irma (2018), (ed.), Ars Olearia. Dall'oliveto al mercatonel medioevo. Cuneo, CeSA.

Peris AlbentosA, Tomàs (1995), «Evolución de la agricultura valenciana entre los siglos XV-XIX: rasgos cualitativos y problemas de cuantificación», Revista de Historia Económica, 3: 473-508.

PINI, Antonio Ivan (1980), «Due colture specialistiche del Medioevo: la vite e l'olio nell'Italia padana». En Vito Fumagalli y Gabriella Rossetti, Medioevo rurale. Sulle tracce della civiltà contadina. Bolonia, Il Mulino: 119-138.

PINTO, Giuliano (2002), «Glioolivi e l'olio», En Campagne e paesaggi toscani del Medioevo. Florencia, Nardini: 111-132.

SABATÉ I CURULL, Flocel (2018), «Olio e mercati nella Catalogna del basso medioevo». En Irma Naso (ed.), Ars Olearia. Dall'oliveto al mercato nel medioevo. Cuneo, CeSA: 153-192.

SERRANO I JAÉN, Joaquim (1993), «Desenvolupament i destrucció d'una minoria: els moriscos al senyoriu d'Elx», Recerques 27: 62-72.

SESMA MuÑOZ, José Ángel (1992), «Rasgos precapitalistas en la organización industrial aragonesa (siglo XV)», Medievalia, 10: 387-402.

SESMA MuÑOZ, José Ángel (2005), «Centros de producción y redes de distribución en los espacios interiores de la Corona de Aragón. Materias primas y productos bási- 
cos». En Rafael Narbona (coord.), La Mediterrània de la Corona d'Aragó, segles XIII-XVI. $18^{\circ}$ Congrés d'Història de la Corona d'Aragó. Valencia, Universitat de València: 903-938.

TORRAS ElíAs, Jaume (2006), Fabricants sense fàbrica. Els Torrelló d'Igualada (1691-1794). Vic, Eumo.

TORRÓ GIL, Lluís (1996), La Reial fàbrica de draps d'Alcoi. Ordenences gremials (segles XVI-XVIII). Alcoi, Diputació d'Alacant.

TORRÓ GIL, Lluís (2005), «Transformaciones agrarias en el campo valenciano durante la Edad Moderna. El caso de la comarca de Alcoi (ss. XV-XVIII)», Revista de Historia Económica, 23/3: 563-594.

VICIANO, Pau (2008), «Producción agraria e impuesto municipal directo. La tasación de la tierra en los padrones de riqueza (siglos XIV-XV)». En Rafael Vallejo (ed.), Los tributos de la tierra. Valencia, PUV: 245-263.

ViCIANO, Pau (2013), Els peus que calciguen la terra. Els llauradors del País Valencià a la fi de l'edat mitjana. Valencia, PUV. 